\title{
Effects of Bariatric Surgery on Influenza-Like Illness: a Two-Center Cross-sectional Study
}

\author{
Marina Valente ${ }^{1}$ (I) $\cdot$ Giorgio Dalmonte ${ }^{1}$ (I) $\cdot$ Matteo Riccò ${ }^{2}$ (D) $\cdot$ Tarek Debs $^{3} \cdot$ Jean Gugenheim ${ }^{4} \cdot$ Antonio lannelli $^{4}$. \\ Maria Marcantonio ${ }^{3}$ - Alfredo Annicchiarico ${ }^{1}$ (D) - Paolo Del Rio ${ }^{1}$ (D) - Gabriele Luciano Petracca ${ }^{5}$ (D) . \\ Francesco Tartamella ${ }^{5}$ (D) Federico Marchesi $^{1,6}{ }_{\text {(D) }}$
}

Received: 14 January 2021 / Revised: 24 March 2021 / Accepted: 24 March 2021 / Published online: 31 March 2021

(C) The Author(s), under exclusive licence to Springer Science+Business Media, LLC, part of Springer Nature 2021

\section{Dear Editor,}

During the last months, the COVID-19 pandemic revealed the dramatic impact that respiratory viruses can generate on the overall population, with considerable consequences on social dynamics and health-care systems. Although it is generally less severely disrupting, influenza epidemic can nonetheless affect public health, communities, and economies worldwide. In fact, previous estimates indicated that almost $300,000-650,000$ deaths occur annually worldwide due to seasonal influenza viruses [1], contributing to a substantial annual burden of deaths globally. Influenza is a highly contagious respiratory tract infection that affects millions of adults each year; recently, people suffering from obesity have been included in the high-risk population for seasonal influenza, together with children, elderly, and immunocompromised people [2].

The association between excess adiposity and pulmonary comorbidities has long been widely acknowledged, but the role of obesity as a risk factor for infectious diseases has been highlighted much more recently only $[3,4]$. Obesity is indeed

Federico Marchesi

federico.marchesi@unipr.it

1 Unit of General Surgery, Parma University Hospital, University of Parma, Parma, Italy

2 Dipartimento di Sanità Pubblica/Public Health, AUSL-IRCCS Tecnologie Avanzate e Modelli Assistenziali in Oncologia di Reggio Emilia, Reggio Emilia, Italy

3 Digestive Surgery and Liver Transplantation Unit, Archet2 Hospital, Centre Hospitalier Universitaire de Nice, Nice, France

4 Digestive Surgery and Liver Transplantation Unit, Archet2 Hospital, Centre Hospitalier Universitaire de Nice, Université Côte d'Azur, Nice, France

5 Unit of General Surgery, Parma University Hospital, Parma, Italy

6 Università degli Studi di Parma, Via Gramsci, 14-43126 Parma, Italy characterized by an altered metabolic milieu, resulting in hormone dysregulation, derailment of the immune response, and creation of a pro-inflammatory environment, which can easily promote infections $[5,6]$.

The literature suggests that obesity delays the clearance of influenza viral load and prolongs shedding duration, resulting in long-term transmission and delayed recovery [7]. In actual fact, adults suffering from overweight and obesity, compared with normal-weight subjects, show higher risk of hospitalization for respiratory illness during seasonal influenza and, furthermore, of prolonged hospital stay [8]. Indeed, during the 2009 influenza pandemic, obesity was recognized as an independent risk factor for severe H1N1 pulmonary infection [9], as well as for the development of influenza-related systemic complications and for increased morbidity and mortality resulting from infection [10].

Moreover, as recently reported, obesity impairs vaccine response to several infectious diseases, affecting, in the case of influenza, the most efficient primary prevention [11].

It is therefore conceivable that, because of its favorable effects on weight loss, obesity-related comorbidities and on overall pulmonary function, bariatric surgery (BS) can contribute to reducing the incidence and improving the clinical course of influenza in patients suffering from obesity.

We investigated the impact of BS on influenza, by comparing the clinical course of influenza-like illness (ILI) in patients who had undergone BS to that in adult with obesity candidates for a bariatric procedure in a retrospective observational study involving 2 major centers of BS in Italy and France. Data regarding patients that had undergone a bariatric procedure were compared with those of subjects with obesity waiting for surgery in the above-mentioned hospitals. All the subjects completed a web-based questionnaire (Google ${ }^{\circledR}$ FORMS). Clinical expression of influenza virus infection was assessed by measuring illness-related symptoms and outcome parameters, including sick leaves. From the analysis, we 
excluded (a) patients $\leq 18$-year-old at the time of the survey; (b) subjects that had undergone a bariatric procedure other than adjustable gastric band (AGB), sleeve gastrectomy (SG), and Roux-en-Y Gastric By-pass (RYGB); (c) subjects that had undergone the intervention less than 12 months before the beginning of the 2018-2019 seasonal influenza epidemic, as this is considered the minimum time to reach weight loss stabilization and remission of comorbidities [12]. The enrolment period lasted 14 days starting 2 weeks after the end of the 2018-2019 seasonal influenza epidemic in both countries, as stated by the Joint ECDC-WHO Europe weekly Influenza Update report [13]. Data were collected between the 1st and the 14th of March 2019. As period prevalence for influenza-like illnesses in France and Italy during the 20182019 influenza season ranged around 13\%, aiming to an absolute precision of $5 \%$ with a $95 \%$ confidence interval, a minimum sample size of 178 participants was calculated (http:// www.epicentro.iss.it/influenza/FluNews18-19, http:// santepubliquefrance.fr/maladies-et-traumatismes/maladies-etinfections-respiratoires/grippe/documents/article/ surveillance-de-la-grippe-en-france-saison-2018-2019).

The bariatric procedures considered (AGB, SG, and RYGB) account for $89.2 \%$ of all bariatric procedures performed worldwide, being also representative of the Italian and French recent trends in BS [14, 15].

The web-based questionnaire consisted of 37 questions, mostly closed-ended. Data regarding anthropometric characteristics, vaccination history, BS history, comorbidities, influenza-related symptoms, clinical evaluation, and paid sick days were collected.

Among comorbidities and factors able to affect the clinical course of influenza infection, the following were considered: chronic cardiovascular disorders, such as hypertension, arrhythmia, and previous myocardial ischemia; diabetes; smoking habit; and chronic respiratory disorders, including COPD and asthma.

Along with seasonal influenza and pneumococcus vaccine for the examined period, past seasonal influenza vaccination history was recorded, assuming possible residual protection [16].

Influenza-related symptoms included the most predictive symptoms of influenza and other closely related ones, experienced from October 2018 to March 2019: fever $\left(\geq 38^{\circ} \mathrm{C}\right.$ ), fever at rapid onset, shivering, cough, asthenia, myalgia, sore throat, running nose, nausea or vomit, and diarrhea [17].

Any influenza-related medical evaluation, hospital admission or intake of drugs was considered as indicator of severity of the disease. Sick leaves for any influenza-like symptom were considered as an outcome indicator too.

Consistently with the latest definitions given by the World Health Organization (WHO), ILI and Severe Acute Respiratory Infection (SARI) were considered in the analysis. In particular, ILI was defined as an acute respiratory illness with a measured temperature of $\geq 38^{\circ} \mathrm{C}$ and cough, and SARI as an acute respiratory illness with a history of fever or measured fever of $\geq 38^{\circ} \mathrm{C}$ and cough, requiring hospitalization [17]. As per common practice for seasonal influenza, no confirmation laboratory test was considered.

Univariate comparisons were performed by means of chisquared test with Yates correction for dichotomous variables, and with Student's unpaired $t$ test for continuous variables. Four distinctive outcomes were assessed: (a) having received any bariatric surgery, (b) complaints fulfilling ILI definition, (c) any sick leave, and (d) any sick leave $>3$ days. Therefore, initially, we compared characteristics of operated and nonoperated patients, including both demographic characteristics and complained signs/symptoms of seasonal influenza. Then, comparisons of individual characteristics were performed between cases of ILI vs. no-ILI, patients reporting sick leaves during the influenza season vs. cases not reporting sick leaves (any and $>3$ days).

In multivariate analyses, 4 models of binary logistic regression were assessed, which included all variables that, in univariate analysis, were associated with the respective outcome having $p$ value $<0.2$. Corresponding odds ratio (OR) values with their 95\% confidence interval (CI95\%) were then calculated accordingly.

Response rate to the questionnaire was $88 \%$. Out of the 220 patients of 250 who responded to the questionnaire, 36 were excluded because they did not meet the inclusion criteria.

One hundred and three patients operated (Op) and 81 candidates for BS (C) were finally included in the statistical analysis. RYGB was the most common procedure performed (69.9\%), followed by SG (26.2\%), and AGB (3.9\%). Op and C groups were similar for age and sex proportion (Table 1).

As predictable effect of BS, Op patients presented a significant lower BMI and lower incidence of metabolic comorbidities, such as diabetes $(9.7 \%$ vs $29.6 \%, p: 0.001)$. No significant difference was found in smoking habits and in previous respiratory and cardiovascular disorders. Vaccination history was similar in the two groups, too. One hundred sixty-one patients $(87.5 \%)$ reported at least one influenza-related symptom, $85.4 \%$ of Op patients and $90.1 \%$ of C patients (Table 1). In particular, among Op patients, we recorded lower incidence of fever, of fever with rapid onset $(48.1 \%$ vs $20.4 \%$ and $44.4 \%$ vs $14.6 \%, p<0.001$, respectively), resulting in lower incidence of ILI among Op patients (13.6\% vs $34.6 \%, p$ : 0.001 ). We reported a lower intake of non-steroid anti-inflammatory drugs (NSAIDs) among Op patients (20.4 vs $42.0 \%$, $p$ : 0.003 ), as well as a higher rate of evaluation by a general practitioner (GP) in C patients, both as practice and in-home assessment (45\% vs $23.3 \%, p$ : 0.003 and $19.8 \%$ vs $2.9 \%, p<$ 0.001 , respectively). A total of $13.6 \%$ of $\mathrm{C}$ patients was admitted to the emergency department vs $3.9 \%$ of Op patients ( $p$ : 0.034). A higher percentage of sick leave was found among $C$ patients $(42.0 \%$ vs $22.3 \%, p$ : 0.007$)$, who had also a higher rate of prolonged ( $>3$ days) leaves $(22.2 \%$ vs $8.7 \%$, 
Table 1 Demographics, symptoms, outcomes

\begin{tabular}{|c|c|c|c|c|}
\hline & Total $(N=184)$ & Op $(N=103)$ & $\mathrm{C}(N=81)$ & $P$ value \\
\hline Gender $(N, \%)$ & & & & 0.458 \\
\hline Male & 4423.9 & 2221.4 & 2227.2 & \\
\hline Female & 14076.1 & 8178.6 & 6572.8 & \\
\hline Age (years; average $\pm \mathrm{SD}$ ) & $48.0 \pm 10.8$ & $48.6 \pm 10.4$ & $47.2 \pm 11.2$ & 0.380 \\
\hline left $(N, \%)$ & & & & 0.014 \\
\hline Italy & 11059.8 & 5351.5 & 5770.4 & \\
\hline France & 7440.2 & 5048.5 & 2429.6 & \\
\hline \multicolumn{5}{|l|}{ Surgical procedure $(N, \%)$} \\
\hline RYGB & 7239.1 & 7269.9 & - & \\
\hline SG & 2714.7 & 2726.2 & - & \\
\hline AGB & 42.2 & 43.9 & - & \\
\hline BMI $\left(\mathrm{kg} / \mathrm{m}^{2} ;\right.$ average $\left.\pm \mathrm{SD}\right)$ & $35.6 \pm 9.6$ & $29.4 \pm 5.6$ & $43.4 \pm 7.6$ & $<0.001$ \\
\hline Status by BMI $(N, \%)$ & & & & $<0.001$ \\
\hline Normal weight $\left(<25 \mathrm{~kg} / \mathrm{m}^{2}\right)$ & 2312.5 & 2322.3 & $0-$ & \\
\hline Overweight (25-29.9 kg/m²) & 3619.6 & 3635.0 & $0-$ & \\
\hline Obesity 1 st class $\left(30-34.9 \mathrm{~kg} / \mathrm{m}^{2}\right)$ & 3317.9 & 2625.2 & 78.5 & \\
\hline Obesity 2nd class (35-39.9 kg/m²) & 3820.7 & 1312.6 & 2530.9 & \\
\hline Obesity 3 rd class $\left(\geq 40 \mathrm{~kg} / \mathrm{m}^{2}\right)$ & 5429.3 & 54.9 & 4960.5 & \\
\hline \multicolumn{5}{|l|}{ Vaccination history $(N, \%)$} \\
\hline SIV during previous winter season & 4423.9 & 2423.3 & 2024.7 & 0.964 \\
\hline Any uptake of SIV, previous years & 5429.3 & 3231.1 & 2227.2 & 0.678 \\
\hline Pneumococcal vaccination, any & 52.7 & 21.9 & 33.7 & 0.785 \\
\hline \multicolumn{5}{|l|}{ Comorbidities $(N, \%)$} \\
\hline Any respiratory disorder & 2915.8 & 1716.5 & 1214.8 & 0.914 \\
\hline Any cardiovascular disorder & 4926.9 & 2726.5 & 2227.5 & 1.000 \\
\hline Diabetes & 3418.5 & 109.7 & 2429.6 & 0.001 \\
\hline Smoking history $(N, \%)$ & 11260.9 & 6260.2 & 5061.7 & 0.953 \\
\hline \multicolumn{5}{|l|}{ Symptoms $(N, \%)$} \\
\hline Fever (body temperature $>38^{\circ} \mathrm{C}$ ) & 6032.6 & 2120.4 & 3948.1 & $<0.001$ \\
\hline Fever, sudden onset & 5127.7 & 1514.6 & 3644.4 & $<0.001$ \\
\hline Sore throat & 10054.3 & 4846.6 & 5264.2 & 0.026 \\
\hline Running nose & 1163.0 & 6361.2 & 5365.4 & 0.659 \\
\hline Cough & 9350.5 & 4543.7 & 4859.3 & 0.051 \\
\hline Shivering & 8646.7 & 4846.6 & 3846.9 & 1.000 \\
\hline Muscle pain & 9048.9 & 4745.6 & 4354.1 & 0.392 \\
\hline Nausea & 5329.0 & 2625.2 & 2733.8 & 0.274 \\
\hline Diarrhea & 7440.2 & 4038.8 & 3442.0 & 0.780 \\
\hline Asthenia & 9149.5 & 5048.5 & 4150.6 & 0.896 \\
\hline ILI (fever + cough) & 4222.8 & 1413.6 & 2834.6 & 0.001 \\
\hline SARI (ILI + hospital admission) & 126.5 & 43.9 & 89.9 & 0.182 \\
\hline Any symptom & 16187.5 & 8885.4 & 7390.1 & 0.466 \\
\hline More than 3 symptoms & 11562.5 & 5755.3 & 5871.6 & 0.035 \\
\hline \multicolumn{5}{|l|}{ Drug uptake $(N, \%)$} \\
\hline Paracetamol & 12669.6 & 7168.9 & 5570.5 & 0.948 \\
\hline Painkillers & 9451.1 & 4947.6 & 4555.6 & 0.354 \\
\hline NSAIDS & 5529.9 & 2120.4 & 3442.0 & 0.003 \\
\hline Antibiotics & 6032.8 & 2827.2 & 3240.0 & 0.094 \\
\hline Antiviral drugs & 73.8 & 21.9 & 56.2 & 0.271 \\
\hline Antitussive drugs & 5630.4 & 2726.2 & 2935.8 & 0.214 \\
\hline
\end{tabular}


Table 1 (continued)

\begin{tabular}{|c|c|c|c|c|}
\hline & Total $(N=184)$ & Op $(N=103)$ & $\mathrm{C}(N=81)$ & $P$ value \\
\hline Nasal sprays & 6233.7 & 2928.2 & 3340.7 & 0.102 \\
\hline \multicolumn{5}{|l|}{ Medical evaluation $(N, \%)$} \\
\hline Assessment by GP for any malaise & 6032.8 & 2423.3 & 3645.0 & 0.003 \\
\hline Home assessment by GP & 1910.3 & 32.9 & 1619.8 & $<0.001$ \\
\hline Evaluation by a medical specialist & 147.6 & 65.8 & 89.9 & 0.454 \\
\hline Admission to emergency department & 158.2 & 43.9 & 1113.6 & 0.034 \\
\hline Sick leave $(N, \%)$ & 5731.0 & 2322.3 & 3442.0 & 0.007 \\
\hline Length of sick leave (days; mean $\pm \mathrm{SD}$ ) & $4.6 \pm 4.9$ & $3.1 \pm 1.9$ & $5.7 \pm 6.0$ & 0.028 \\
\hline Sick leave $>3$ days $(N, \%)$ & $27,14.7$ & $9,8.7$ & $18,22.2$ & 0.018 \\
\hline
\end{tabular}

$O p$ operated patients, $C$ candidates for surgery, $R Y G B$ Roux-en-Y Gastric Bypass, $S G$ sleeve gastrectomy, $A G B$ adjustable gastric banding; $B M I$ body mass index, $S I V$ seasonal influenza vaccination, $I L I$ influenza-like illness, $S A R I$ severe acute respiratory syndrome, NSAID non-steroid anti-inflammatory drug, GP general practitioner

$p$ : 0.018). Fever, sore throat, in-home assessment by GPs, and sick leaves $>3$ days showed to be inversely associated with $\mathrm{BS}$ also at multivariate analysis.

Univariate analysis indicated BMI and obesity (body mass index $(\mathrm{BMI}) \geq 30 \mathrm{~kg} / \mathrm{m}^{2}$ ) as related to ILI ( $p$ : 0.046 and $p$ : 0.017 , respectively), to sick leave ( $p: 0.007$ and $p: 0.001$, respectively), and to prolonged leaves ( $p$ : 0.003 and $p$ : 0.004 , respectively) (Table 2). Diabetes showed a significant correlation with sick leave and prolonged leaves $(p: 0.001$ and $p$ : 0.003 , respectively).

At multivariate analysis, both obesity and diabetes confirmed to be associated with sick leave and to prolonged leaves, while the presence of underlying respiratory diseases showed a correlation with ILI (Table 3 ).

The lower incidence of influenza-related symptoms and ILI among Op patients in our series are consistent with recently published data [18], reporting significantly lower risk of respiratory infections in a cohort of Taiwanese patients who underwent BS.

The effect of BS on weight loss and improvement in the main obesity-related comorbidities is undoubted. Moreover, it is conceivable that $\mathrm{BS}$ could decrease the risk of respiratory infectious diseases, even though, to date, available evidence in the literature is limited.

Severe obesity could promote the clinical expression of influenza viruses, as recently reported for Sars-CoV-2 infection [19, 20]. Obesity is in fact characterized by chronic low-grade inflammation, with subsequent impairment of the immune system, and it is also associated with reduced lung function and decreased respiratory compliance, leading to higher risk of obstructive syndrome and pneumonia [5, 6]. The literature gives clear evidence that sustained weight loss after BS is associated with reduced

Table 2 Univariate analysis

\begin{tabular}{|c|c|c|c|c|c|c|c|c|c|}
\hline & \multicolumn{2}{|l|}{ ILI } & \multirow[b]{2}{*}{$P$ value } & \multicolumn{2}{|l|}{ Sick leave } & \multirow[b]{2}{*}{$P$ value } & \multicolumn{2}{|c|}{ Sick leave $>3$ days } & \multirow[b]{2}{*}{$P$ value } \\
\hline & $\begin{array}{l}\text { Pos. } \\
(N=42)\end{array}$ & $\begin{array}{l}\text { Neg. } \\
(N=142)\end{array}$ & & $\begin{array}{l}\text { Pos. } \\
(N=57)\end{array}$ & $\begin{array}{l}\text { Neg. } \\
(N=127)\end{array}$ & & Pos. $(N=27)$ & Neg. $(N=157)$ & \\
\hline Male gender $(N, \%)$ & 921.4 & 3524.6 & 0.823 & 1322.8 & 3124.4 & 0.961 & 518.5 & 3924.8 & 0.640 \\
\hline Age (ys, average \pm S.D.) & $\begin{array}{l}48.7 \\
\quad \pm 10.6\end{array}$ & $45.7 \pm 10.9$ & 0.109 & $\begin{array}{l}46.6 \\
\quad \pm 10.3\end{array}$ & $\begin{array}{l}48.7 \\
\quad \pm 10.9\end{array}$ & 0.275 & $48.7 \pm 10.9$ & $43.9 \pm 9.2$ & 0.030 \\
\hline BMI (average \pm S.D.) & $38.0 \pm 8.6$ & $34.9 \pm 9.8$ & 0.046 & $38.3 \pm 8.3$ & $34.4 \pm 9.9$ & 0.007 & $40.1 \pm 7.6$ & $34.8 \pm 9.7$ & 0.003 \\
\hline Obesity $(N, \%)$ & 3583.3 & 8862.0 & 0.017 & 4884.2 & 7559.1 & 0.001 & 2592.6 & 9862.4 & 0.004 \\
\hline SIV during previous winter season $(N, \%)$ & 819.0 & 3625.4 & 0.525 & 1119.3 & 3426.9 & 0.426 & 518.5 & 3924.8 & 0.640 \\
\hline Any previous uptake of SIV $(N, \%)$ & 1126.2 & 4330.3 & 0.750 & 1221.1 & 4233.1 & 0.139 & 518.5 & 4931.2 & 0.267 \\
\hline Pneumococcal vaccine $(N, \%)$ & 24.8 & 32.1 & 0.698 & $0-$ & 53.9 & 0.304 & $0-$ & 53.2 & 0.765 \\
\hline Respiratory disease $(N, \%)$ & 1023.8 & 1913.4 & 0.165 & 1221.1 & 1713.4 & 0.271 & 414.8 & 2515.9 & 1.000 \\
\hline Diabetes $(N, \%)$ & 1126.2 & 2316.2 & 0.215 & 1933 & 1511.8 & 0.001 & 1140.7 & 2314.6 & 0.003 \\
\hline Cardiovascular disease $(N, \%)$ & 819.5 & 4129.1 & 0.310 & 1628.6 & 3326.2 & 0.878 & 829.6 & 4126.5 & 0.914 \\
\hline Smoking history $(N, \%)$ & 2661.9 & 8660.6 & 1.000 & 3764.9 & 7559.1 & 0.556 & 1970.4 & 9359.2 & 0.378 \\
\hline
\end{tabular}

ILI influenza-like illness, $B M I$ body mass index, SIV seasonal influenza vaccination 
Table 3 Multivariate analysis

\begin{tabular}{|c|c|c|c|c|c|c|c|c|}
\hline & \multicolumn{2}{|l|}{ BS } & \multicolumn{2}{|l|}{ ILI } & \multicolumn{2}{|c|}{ Sick leave } & \multicolumn{2}{|c|}{$\begin{array}{l}\text { Sick leave }>3 \\
\text { days }\end{array}$} \\
\hline & OR & $95 \% \mathrm{CI}$ & OR & $95 \% \mathrm{CI}$ & OR & $95 \% \mathrm{CI}$ & OR & $95 \% \mathrm{CI}$ \\
\hline Obesity & - & - & 1.116 & $\begin{array}{l}0.412 \\
3.027\end{array}$ & 3.151 & $\begin{array}{l}1.352 \\
7.342\end{array}$ & 9.097 & $\begin{array}{l}1.859 \\
44.519\end{array}$ \\
\hline Respiratory disease & - & - & 2.783 & $\begin{array}{l}1.100 \\
7.044\end{array}$ & - & - & - & - \\
\hline Diabetes & 0.359 & $\begin{array}{l}0.092 \\
1.404\end{array}$ & - & - & 3.569 & $\begin{array}{l}1.534 \\
8.300\end{array}$ & 4.231 & $\begin{array}{l}1.533 \\
11.678\end{array}$ \\
\hline Previous SIV & - & - & & & 0.538 & $\begin{array}{r}0.247 \\
1.174\end{array}$ & 0.658 & $\begin{array}{l}0.217 \\
1.992\end{array}$ \\
\hline Fever & 0.097 & $\begin{array}{r}0.010 \\
0.967\end{array}$ & - & - & - & - & - & - \\
\hline Fever-sudden onset & 0.306 & $\begin{array}{l}0.083 \\
1.129\end{array}$ & - & - & - & - & - & - \\
\hline Sore throat & 0.102 & $\begin{array}{r}0.021 \\
0.489\end{array}$ & - & - & - & - & - & - \\
\hline Cough & 1.355 & $\begin{array}{l}0.493 \\
3.726\end{array}$ & & & & & & \\
\hline More than 3 symptoms & 0.090 & $\begin{array}{l}0.018 \\
0.442\end{array}$ & & & & & & \\
\hline ILI & 0.172 & $\begin{array}{r}0.019 \\
1.567\end{array}$ & & & & & & \\
\hline SARI & 0.857 & $\begin{array}{l}0.068 \\
10.857\end{array}$ & & & & & & \\
\hline Uptake of NSAIDs & 0.575 & $\begin{array}{l}0.221 \\
1.492\end{array}$ & & & & & & \\
\hline Uptake of antibiotics & 1.785 & $\begin{array}{r}0.661 \\
4.891\end{array}$ & & & & & & \\
\hline Nasal sprays & 0.560 & $\begin{array}{r}0.232 \\
1.354\end{array}$ & & & & & & \\
\hline Assessment by GP & 0.771 & $\begin{array}{l}0.252 \\
2.361\end{array}$ & - & - & - & - & - & - \\
\hline Home assessment by GP & 0.240 & $\begin{array}{l}0.042 \\
0.963\end{array}$ & - & - & - & - & - & - \\
\hline $\begin{array}{l}\text { Admission to emergency } \\
\text { department }\end{array}$ & 0.439 & $\begin{array}{l}0.044 \\
4.332\end{array}$ & - & - & - & - & - & - \\
\hline Any sick leave & 0.543 & $\begin{array}{l}0.144 \\
2.051\end{array}$ & & & & & & \\
\hline Sick leave $>3$ days & 0.198 & $\begin{array}{l}0.038 \\
0.930\end{array}$ & - & - & - & - & - & - \\
\hline
\end{tabular}

$B S$ bariatric surgery, $I L I$ influenza-like illness, $S I V$ seasonal influenza vaccination, $S A R I$ severe acute respiratory syndrome, NSAID non-steroid anti-inflammatory drug, GP general practitioner

low-grade inflammation markers and improved pulmonary function, thus ameliorating symptomatic asthma and obstructive sleep apnea syndrome [21].

In the light of the above, an improvement in outcome parameters was expected in our series and has been confirmed by the better performance of Op patients in NSAIDs and antiviral drug use, evaluation by GP and admission to the emergency department.

The difference among $\mathrm{Op}$ and $\mathrm{C}$ patients in sick leaves and prolonged leaves confirms the outcome trend, highlighting the social and economic implications of the disease.

Comorbidity resolution could also contribute to the better clinical outcome of Op patients.

Individuals with obesity are indeed at higher risk of other chronic diseases, such as hypertension, dyslipidemia, insulin resistance, and metabolic syndrome, which can be responsible for a more severe course of respiratory tract infections. In particular, both univariate and multivariate analyses suggest a correlation of diabetes with sick leave and prolonged leaves, in line with previous studies reporting a higher risk for diabetic patients to suffer from more severe influenza, to be hospitalized, or to require ICU care [22, 23].

Vaccination before seasonal influenza outbreaks is still the most effective preventive measure. Nevertheless, studies of vaccine efficacy have shown a significant interindividual variability, on which obesity could play a role. In particular, increased BMI is associated with a reduction in the protective immune response over time, because of decreased activation of immunocompetent cells [11]; as a consequence, vaccinated patients suffering from obesity have a twofold risk of developing influenza or ILI compared with vaccinated healthy weight adults [24]. Paradoxically, the population with obesity, who would benefit the most from the 
influenza vaccine, at the same time shows a lower response to it. Indeed, in our series, we did not observe any correlation of vaccination history with ILI or with parameters of severe infection, probably due to the small sample size. Larger series should assess whether a vaccination strategy mainly focused on patients with obesity may be reasonable.

Despite the limits of the study, including the small sample size, the self-completion of the questionnaire leading to a not "clinical" diagnosis of ILI, and the lack of a laboratory confirmation of influenza, our series suggests a protective role of BS against ILI.

Further studies are needed to better define the role of weight loss and, in particular, of BS, among the preventive measures against influenza and respiratory tract infections.

The questionnaire will be made available on request by the corresponding author.

Acknowledgements Vittoria Pattonieri, Chiara Rapacchi, Marta Ribolla, Francesco Rubichi, Andrea Romboli, and Giovanna Rosati contributed equally to this work.

Declarations Informed consent was obtained from all individual participants included in the study.

All procedures performed in studies involving human participants were in accordance with ethical standards of the institutional and/or national research committee and with the 1964 Helsinki declaration and its later amendments or comparable ethical standards.

Conflict of Interest The authors declare no competing interests.

\section{References}

1. Iuliano AD, Roguski KM, Chang HH, et al. Estimates of global seasonal influenza-associated respiratory mortality: a modelling study. Lancet. 2018;391:1285-300.

2. Centers for Disease Control and Prevention. People who are at higher risk for severe illness. CDC. Centers Dis Control Prev. 2020.

3. Milner JJ, Beck MA. The impact of obesity on the immune response to infection. Proc Nutr Soc. 2012;71:298-306.

4. Huttunen R, Syrjänen J. Obesity and the risk and outcome of infection. Int J Obes (Lond). 2013;37(3):333-40. https://doi.org/10. 1038/ijo.2012.62.

5. Nave H, Beutel G, Kielstein JT. Obesity-related immunodeficiency in patients with pandemic influenza H1N1. Lancet Infect Dis. 2011;11:14-5.

6. Ubags ND, Stapleton RD, Vernooy JH, et al. Hyperleptinemia is associated with impaired pulmonary host defense. JCI Insight. 2016;1(8):e82101. https://doi.org/10.1172/jci.insight.82101.

7. Maier HE, Lopez R, Sanchez N, et al. Obesity increases the duration of influenza a virus shedding in adults. J Infect Dis. 2018;218: 1378-82.

8. Kwong JC, Campitelli MA, Rosella LC. Obesity and respiratory hospitalizations during influenza seasons in Ontario, Canada: a cohort study. Clin Infect Dis. 2011;53:413-21.
9. Van Kerkhove MD, Vandemaele KA, Shinde V, et al; WHO Working Group for Risk Factors for Severe H1N1pdm Infection. Risk factors for severe outcomes following 2009 influenza A (H1N1) infection: a global pooled analysis. PLoS Med. 2011;8(7):e1001053. https://doi.org/10.1371/journal.pmed. 1001053.

10. Louie JK, Acosta M, Samuel MC, et al. A novel risk factor for a novel virus: obesity and 2009 pandemic influenza a (H1N1). Clin Infect Dis. 2011;52:301-12.

11. Sheridan PA, Paich HA, Handy J, et al. Obesity is associated with impaired immune response to influenza vaccination in humans. Int J Obes. 2012;36:1072-7.

12. Courcoulas AP, King WC, Belle SH, et al. Seven-year weight trajectories and health outcomes in the Longitudinal Assessment of Bariatric Surgery (LABS) study. JAMA Surg. 2018;153:427-34.

13. European Centre for Disease Prevention and Control/WHO Regional Office for Europe Flu News Europe, Joint ECDC-WHO weekly influenza update, week 10/2019.

14. Debs T, Petrucciani N, Kassir R, et al. Trends of bariatric surgery in France during the last 10 years: analysis of 267,466 procedures from 2005-2014. Surg Obes Relat Dis. 2016;12(8):1602-9. https://doi.org/10.1016/j.soard.2016.05.010.

15. Welbourn R, Hollyman M, Kinsman R, et al. Bariatric surgery worldwide: baseline demographic description and one-year outcomes from the Fourth IFSO Global Registry Report 2018. Obes Surg. 2019;29:782-95.

16. Ramsay LC, Buchan SA, Stirling RG, et al. The impact of repeated vaccination on influenza vaccine effectiveness: a systematic review and meta-analysis. BMC Med. 2019;17:9.

17. Fitzner J, Qasmieh S, Mounts AW, et al. Revision of clinical case definitions: Influenza-like illness and severe acute respiratory infection. Bull World Health Organ. 2018;96:122-8.

18. Chen JH, Wei YF, Chen CY, et al. Decreased long-term respiratory infection risk after bariatric surgery: a comprehensive national cohort study. Obes Surg. 2021;31(2):499-507. https://doi.org/10. 1007/s11695-020-05001-5.

19. Marchesi F, Valente M, Riccò M, et al. Effects of bariatric surgery on COVID-19: a multicentric study from a high incidence area. Obes Surg. 2021; Available from:; https://doi.org/10.1007/ s11695-020-05193-w.

20. Iannelli A, Bouam S, Schneck AS, Frey S, Zarca K, Gugenheim J, et al. The Impact of Previous History of Bariatric Surgery on Outcome of COVID-19. A Nationwide Medico-Administrative French Study. Obes Surg. Springer; 2020 [cited 2021 Jan 14];19. Available from: https://doi.org/10.1007/s11695-020-05120-z

21. Tirado R, Masdeu MJ, Vigil L, et al. Impact of bariatric surgery on heme oxygenase-1, inflammation, and insulin resistance in morbid obesity with obstructive sleep apnea. Obes Surg. 2017;27:2338-46.

22. Allard R, Leclerc P, Tremblay C, et al. Diabetes and the severity of pandemic influenza A (H1N1) infection. Diabetes Care. 2010;33: 1491-3.

23. Hulme KD, Gallo LA, Short KR. Influenza virus and glycemic variability in diabetes: a killer combination? Front Microbiol. 2017;8:861. https://doi.org/10.3389/fmicb.2017.00861.

24. Rojas-Osornio SA, Cruz-Hernández TR, Drago-Serrano ME, et al. Immunity to influenza: impact of obesity. Obes Res Clin Pract. 2019;13:419-29.

Publisher's Note Springer Nature remains neutral with regard to jurisdictional claims in published maps and institutional affiliations. 